\title{
EFFECTS OF CNC MILLING MACHINING PARAMETERS ON THE SURFACE ROUGHNESS OF UHMWPE BIOMATERIAL
}

\author{
Budi Basuki ${ }^{1}$, Andhi Akhmad Ismail ${ }^{2}$ \\ ${ }^{1}$ Departemen Teknik Mesin, Sekolah Vokasi, Universitas Gadjah Mada, Yogyakarta, Republic of Indonesia \\ ${ }^{2}$ Departemen Teknik Mesin, Sekolah Vokasi, Universitas Gadjah Mada, Yogyakarta, Republic of Indonesia
}

\begin{abstract}
Ultra High Molecular Weight Poly Ethylene (UHMWPE) is a plastic biomaterial developed and had been used for decades in biomedical applications. This material is commonly produced with machining processes. One of those process is the milling operation. This method is needed alongside with the more common turning operation since there are many implant designs are not geometrically cylindrical. The milling process like any other machining techniques requires the operators to set certain machining parameter values to achieve specific objectives. One of these is the surface roughness of the materials. Rough machined surfaces were suspected to harbor more bacteria when the implant products made from UHMWPE are being used inside the human body. This study tested the influences of feed rate and depth of cut machining parameters on the UHMWPE surface roughness. The milling machining process with a SIEMENS CNC machine on the UHMWPE biomaterial was proved capable to produce better surface finish qualities. Four feed rate values between $0.2 \mathrm{~mm} / \mathrm{rev}$. to $0.025 \mathrm{~mm} / \mathrm{rev}$. and three depth of cuts from $0.2 \mathrm{~mm}$ down to $0.05 \mathrm{~mm}$ were evaluated. Third machining parameter, i.e. cutting speed was set constant at 150 $\mathrm{m} / \mathrm{minute}$. The tool is the high speed steel end milling. Achieved minimum surface roughness was found below 2 microns. A multiple regression model was developed to guide the machine tool operators to determine proper machining parameters. Statistical tests conducted and it can be concluded that feed rate is the most influential parameter. It must be set $0.05 \mathrm{~mm} / \mathrm{rev}$. or lower in the purpose to obtain higher quality surface finish.
\end{abstract}

Keywords: Biomaterial, UHMWPE, CNC Milling, and Surface roughness

\section{INTRODUCTION}

Machining process is a technology capable to produce mechanical parts for various purposes. Although newer techniques proved to be more competitive than machining, from bulk deformation process up to rapid prototyping, those technologies are not yet overcome the surface quality of machined parts. However, material variations especially the nonmetallic, challenge the process planning of machining processes. For example, very ductile materials like plastics, need to be machined with parameters differ than the traditional metallic ones. From this point, there are various studies needed to be performed to guide machine tool operators. One of the special material is the UHMWPE (Ultra High Molecular Weight Poly Ethylene). This plastic is commonly used as a biomaterial implanted in the human body in the orthopedic applications. It has been used for the TKR (Total Knee Replacement) [1], THR (Total Hip Replacement) [2], TAR (Total Ankle Replacement) and CDA (Cervical Disc Arthroplasty) [3] This material is elastic ductile, wear resistant, self-lubricated [4], low thermal conductivity and low melting point. Those combined material properties pushed the machine tool operators to maintain a low generated heat processes through the optimum machining parameters.
The main requirement of UHMWPE implants beside their accurate size is the surface roughness. Coarse surface finish was suspected to have spaces which could host bacteria [5]. Rough UHMWPE surfaces in contact could be smoothed out due to the plastic deformation generated by the contact forces (the tangential and normal forces). This mechanism is not occurs on the free surfaces. Bacteria and other surrounding microorganism could occupy the interstitial spaces of the rough surfaces. At certain point, the population of those foreign agents could cause disease such as inflammation. On the other side, white blood would try to remove foreign agents by engulfing them and bringing out from the body of the patient who use the implanted materials. This process is usually requires protein from the surrounding. This protein adsorption for example from the bones, could reduce the strength and causes another health problems.

Desired surface roughness could be achieved by controlling the machining parameters such as cutting speed (CS), feed rate $(\mathrm{F})$ and depth of cut (DOC). At the same time, there are other purposes those must be achieved, i.e. the reduced cost and machining time. Optimum parameters must be studied, hence the purpose of this research. The interaction between parameters is also modelled for the purposes to express any correlation or significance. 


\subsection{Literature Study}

Studies on the optimum machining parameters for UHMWPE cutting processes had been conducted by many researchers. Salles and Gonçalves studied the effects of those parameters on the UHMWPE surface qualities [6]. The machining process was a turning operation with EMCO Turn 120 CNC machines and Sandvik Coromant DCGX070204 AL cutting tools. The researchers found that feed rate is the significant parameter influenced surface roughness. Other similar research conducted by [7]. This works mainly focused on careful planning of the optimum machining parameters selection thru the L27 orthogonal array Taguchi method. The materials and the type of machine tool are the same as [6]. Lathe or turning operation fits for the production of cylindrical parts. Meanwhile, many orthopedic implants which use UHMWPE are not geometrically cylindrical except the acetabular cup of hip implants. Other machining process which should be used is the milling operation. It has multi point contacts between tools and work piece. At least two contact points occur with the use of two flute standard milling tools. This type of contact should influence on the achieved surface roughness significantly different with the single point turning operations. The surface roughness of typical machined polyethylene is several microns. Surface roughness obtained by [8] on the machining with turret mill machine were around 1-2 microns. According to [9], the average peak to valley were 2-6 microns for direct molded UHMWPE bearings and 4.8-11.2 microns for the machined bearings. On the GUR 1050 UHMWPE specimens, the maximum height of surface profile can be as high as five microns [10].

\subsection{Materials and Method}

Pure and non-irradiated UHMWPE materials were cut with CNC milling surface finish operations. The cut was a linear plane cutting (Fig -1). Those finishing operations were preceded by face milling operations to set equal initial surface conditions for all specimens. Two machining parameters were studied, i.e. feed rate and depth of cut. The range of those parameters are four feed rates from 0.025 $\mathrm{mm} / \mathrm{rev}$. up to $0.2 \mathrm{~mm} / \mathrm{rev}$. and three variations of depth of cut from $0.025 \mathrm{~mm}$ up to $0.2 \mathrm{~mm}$. Cutting speed was set constant at $150 \mathrm{~m} /$ minute The machine used a SIEMENS programmable controller with dimensional accuracy up to $0.01 \mathrm{~mm}$.

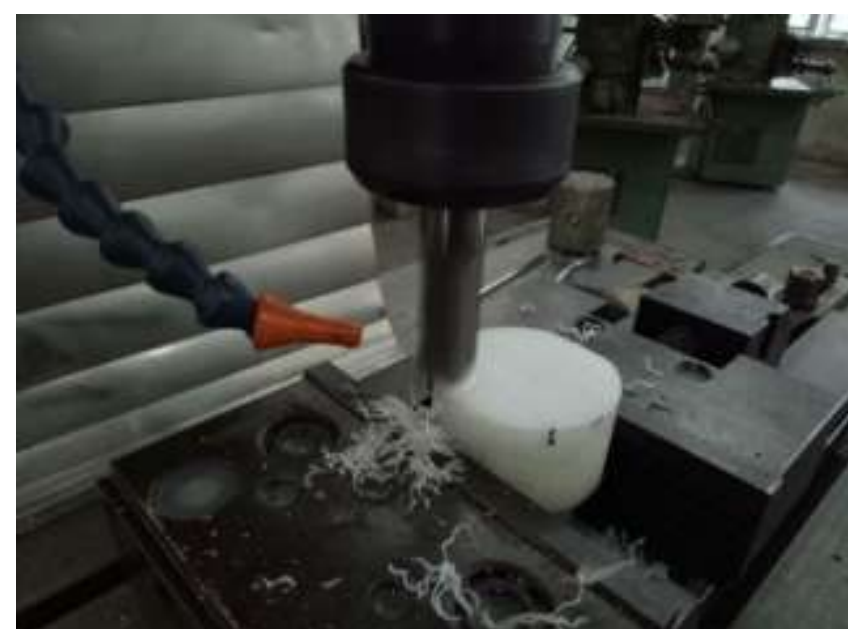

Fig 1: The machining process situation

Cutting tool used in this research was a standard HSS end mill at various diameter to meet the required cutting speed values. UHMWPE chips and debris could easily cause the tools to become dull. Hence a cleaning processes with compressed air were frequently conducted on the cutting tools.

The surface roughness of machined specimens were then measured with a Fowler profilometer. Cut-off length $(\lambda)$ was set fixed at $0.8 \mathrm{~mm}$ and the measured length was five times of $\lambda$. The instrument was regularly calibrated with a 3.0 micron standard roughness specimen from the vendor (Fig 2). Each data point was acquired from the mean of five times measurements with errors calculated from the standard deviations. ANOVA statistical analysis conducted on the data set to determine the machining parameter which significantly affected material's surface roughness. Physical surfaces of the specimens were assessed with an optical microscope.

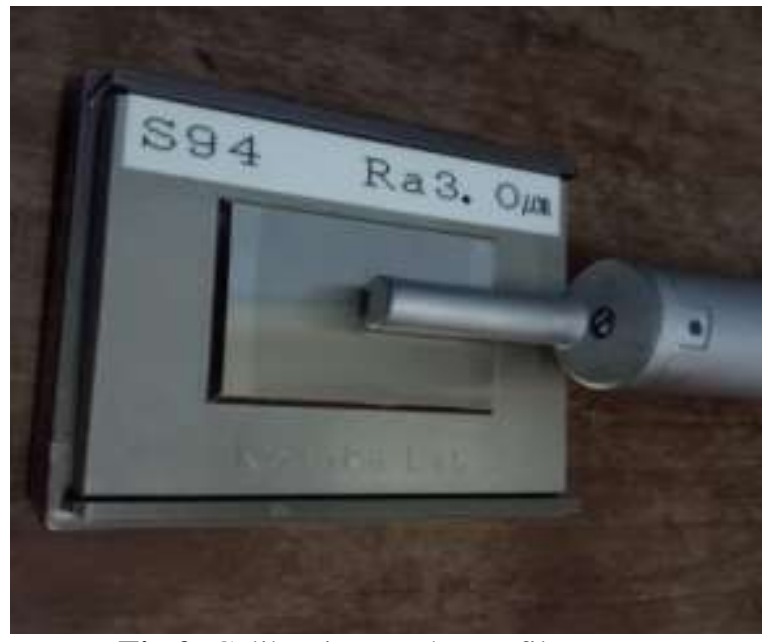

Fig 2: Calibration on the profilometer

Finally, a statistical multi variable mathematical model was built to express the influence of all machining parameters to surface roughness. The method is similar to [11]. 


\section{RESULTS AND DISCUSSION}

A plot of the measured data with respect to feed rate shows linear relations for all depth of cut values (Chart -1). These relations have a consistent trend, the higher feed rate the more rough surface qualities of the specimens.

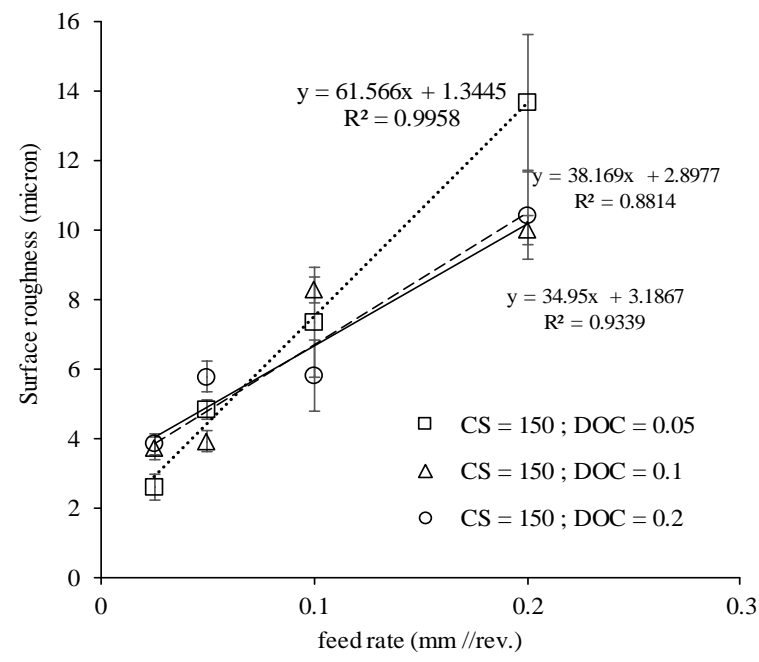

Chart -1: Effect of feed rate on the UHMWPE surface roughness

A unique trend occurs on the cut with a depth of cut of 0.05 $\mathrm{mm}$. With this parameter, minimum surface roughness can be achieved with slower feed $(0.5 \mathrm{~mm} / \mathrm{rev}$. and 0.025 $\mathrm{m} / \mathrm{rev}$ ). Inversely, at higher feed the surfaces are rougher than those surfaces being cut deeper. Too low depth of cut could increase the surface roughness. This phenomena was found by [8] for depths below $0.2 \mathrm{~mm}$.

Effect of depth of cut to surface roughness is less dramatic than feed rate as shown in Chart -2 . The range of error bars show the insignificant difference of roughness at various depth of cut. All trend lines show another view of the significant effect of feed rate as Chart -1 .

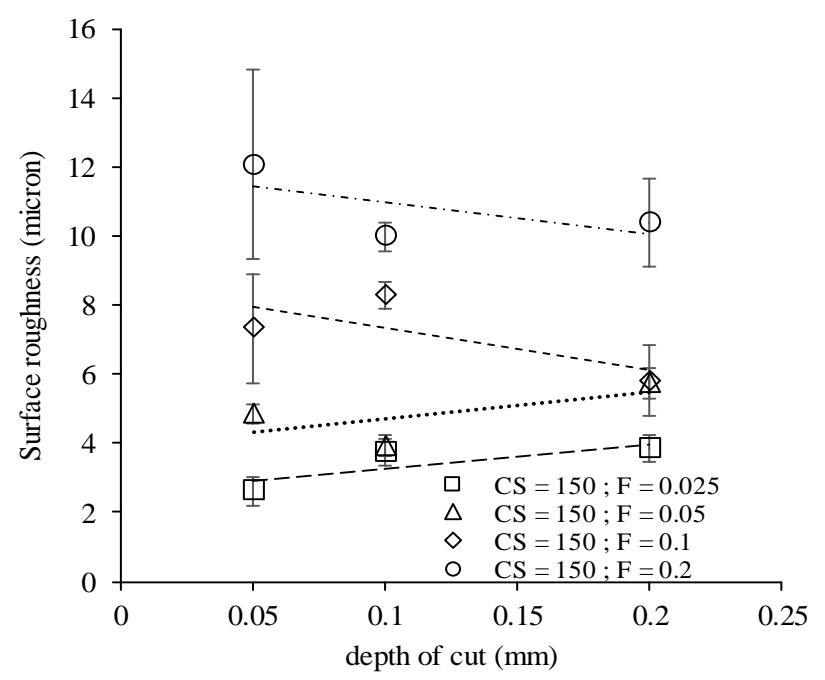

Chart -2: UHMWPE surface roughness as the function of depth of cut
The same data expressed in a radar chart (Chart -3) are now more interpretable. Specimens with all depth of cut variations have rough surfaces at the feed of 0.2 and 0.1 $\mathrm{mm} / \mathrm{rev}$.

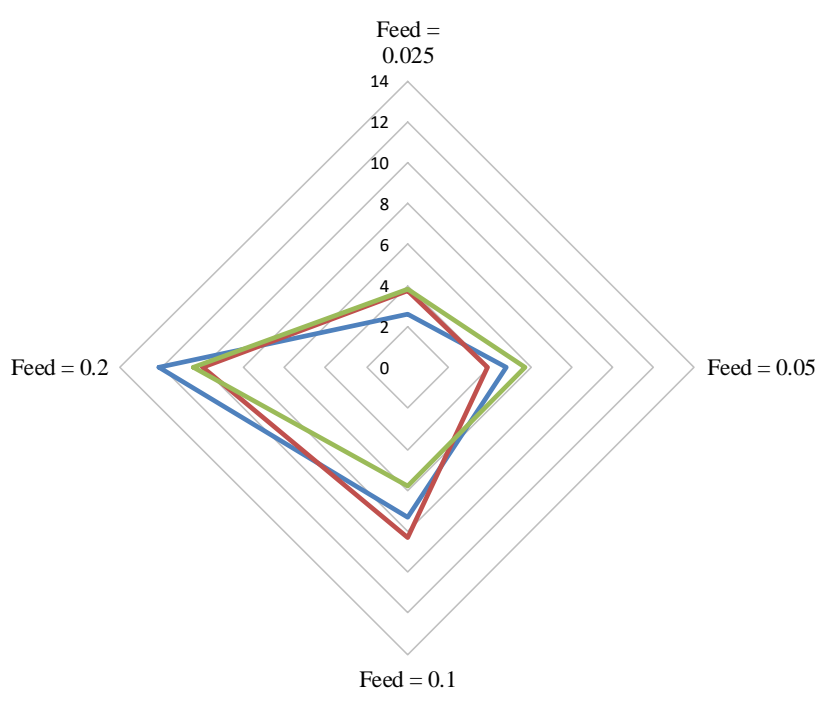

$-\mathrm{DOC}=0.05-\mathrm{DOC}=0.1-\mathrm{DOC}=0.2$

Chart -3: Radar chart express the influence of depth of cut to surface roughness

Surface roughness were reduced significantly with the use of depth of cut equal to $0.05 \mathrm{~mm}$ and $0.1 \mathrm{~mm}$ at the feed of $0.025 \mathrm{~mm} / \mathrm{rev}$. and $0.05 \mathrm{~mm} / \mathrm{rev}$. (quadrat 1 of Chart -3 ).

A three dimensional surface chart of all measured data is useful for mapping the influence of feed rates and depth of cuts simultaneously (Chart -4). Specimens with all tested depth of cuts with feed rate below $0.05 \mathrm{~mm} / \mathrm{rev}$. have much lower surface roughness or better surface finish.

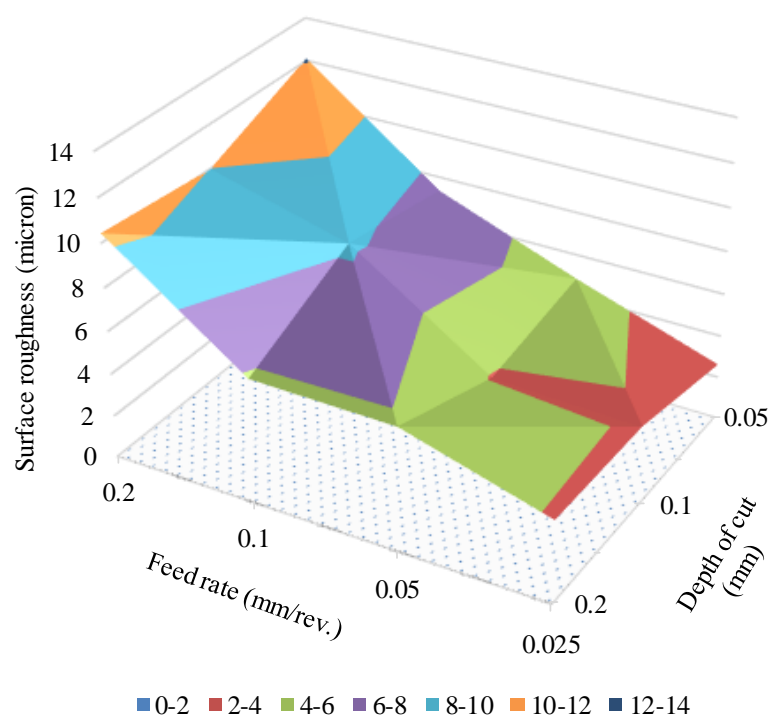

Chart -4: A 3D surface chart shows the effects of feed rate and depth of cut to the UHMWPE surface roughness 
The next step of this study is to determine a significant machining parameter even though visuals from Chart -1 thru Chart -4 show the importance of feed rate qualitatively. The method used statistical analyses to test the parameters based on all achieved results, i.e. surface roughness. One way ANalysis Of VAriance (ANOVA) test results for all machining parameters obtained an $F$ test value (53.224) higher than $F_{\text {crit }}$ value (3.285). The null hypothesis was then should be rejected. It means that the influences of machining parameters to the surface roughness are not equal. One of them must be more significant than others. The $F$ test in ANOVA has some assumptions that the data is normally distributed and the population variances are equal [12]. Results of this statistical analyses show that those assumptions are violated.

Individual parameter significance test and mathematical model development can be conducted with multiple regression method. This model calculates the best fit data with respect of more than one independent variables. All of the obtained research data are not complicated so then it should be adequate to use a Data Analysis module from Microsoft Excel spreadsheet software. This multiple regression algorithm has a built in ANOVA analysis to test the calculated regression model itself. That test is the $F$ test and its significance. The module is also capable to calculate other outputs such as residuals and line fits. Results of the test are shown in Table -1 and Table -2 below:

Table 1: Multiple regression statistics

\begin{tabular}{|c|c|}
\hline Multiple R & 0.957 \\
\hline R Square & 0.915 \\
\hline Adjusted R Square & 0.896 \\
\hline Standard Error & 0.986 \\
\hline
\end{tabular}

Table 2: ANOVA test of the regression model

\begin{tabular}{|c|c|c|}
\hline & F & Significance F \\
\hline Regression & 48.468 & $1.518 \mathrm{E}-05$ \\
\hline
\end{tabular}

\begin{tabular}{|c|c|c|c|c|}
\hline & $\begin{array}{c}\text { Coeffi- } \\
\text { cients }\end{array}$ & $\begin{array}{c}\text { Standard } \\
\text { Error }\end{array}$ & t Stat & p-value \\
\hline Intercept & 2.811 & 0.723 & 3.886 & 0.004 \\
\hline DOC & -1.507 & 4.566 & -0.330 & 0.749 \\
\hline Feed & 41.800 & 4.248 & 9.840 & $4.091 \mathrm{E}-06$ \\
\hline
\end{tabular}

Based on the data of Table 2, the multiple regression model is:

$$
\mathrm{Ra}=2.811+41.8 \mathrm{~F}-1.507 \mathrm{DOC}
$$

with dependent variable $\mathrm{Ra}$ is the surface roughness value in micron. On the $95 \%$ statistical confident, the p-values show that feed rate $(F)$ is the most significant machining parameter with far less than 0.5 and DOC or depth of cut is not significant (more than 0.5). Predicted surface roughness can be calculated based on equation (1) and the results with respect to feed rate and depth of cut were illustrated in Chart -5 and Chart -6 . The high R-squared values of Table -1 still cannot be used to indicate whether the model of equation (1) is appropriate or not. It is then plotted a chart with compare fitted values with residuals (Chart -7). Qualitatively the chart shows a randomness as should appear in a good fit model.

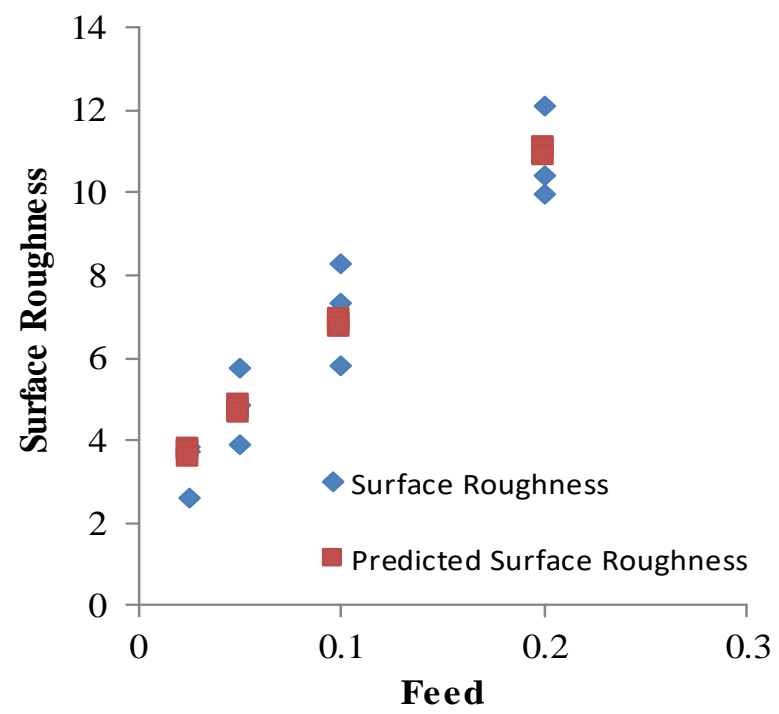

Chart 5: Comparison between predicted and experimental data with respect to feed rate

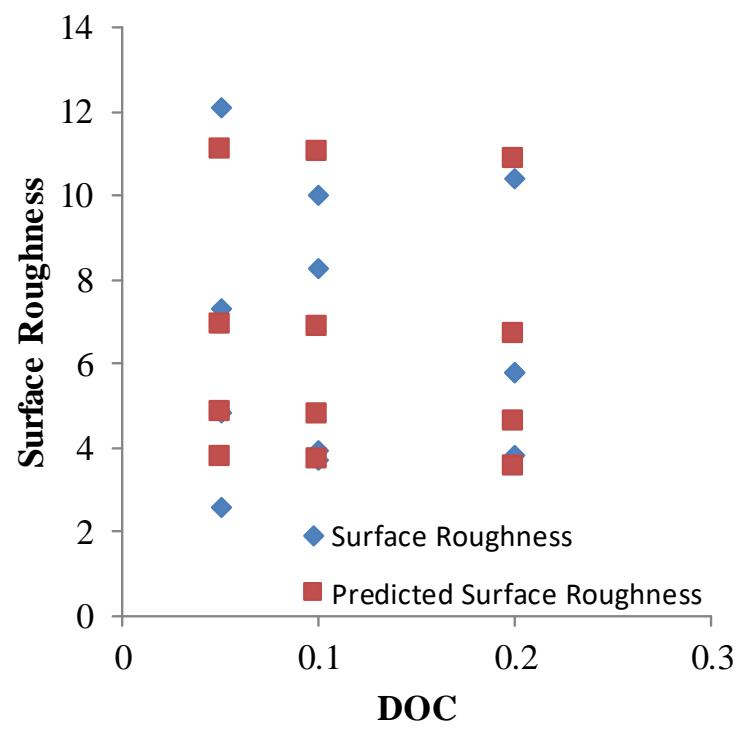

Chart 6: Comparison between predicted and experimental data with respect to depth of cut 


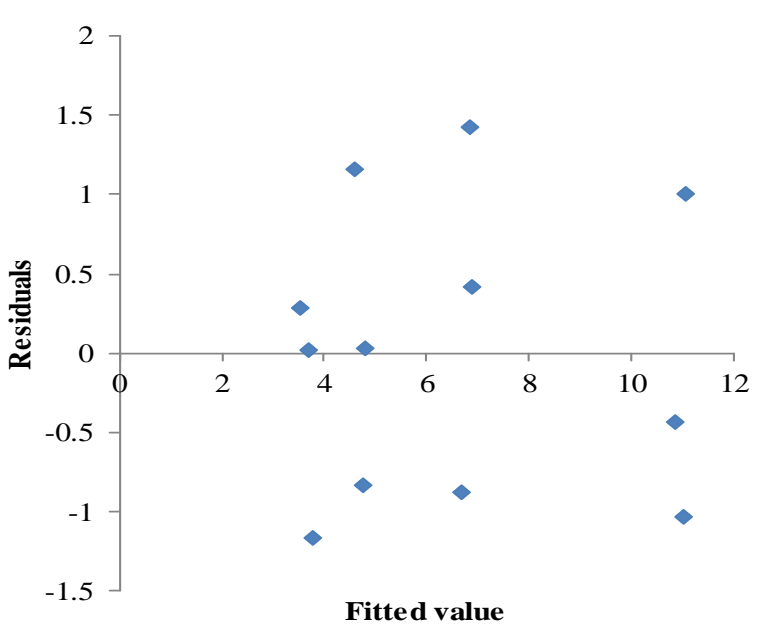

Chart 7: Fitted versus residual plot of the multiple regression model

Visual examinations of the machined surface clearly confirm the difference between rough and smooth surfaces (Fig -3). Waviness in the rough surface is visible and it can be sensed with bare fingers. This phenomena is a sign of the instability of a machining process [13]. It can be concluded that a UHMWPE CNC milling machining process must use feed rate below $0.2 \mathrm{~mm} / \mathrm{rev}$. to obtain a dynamic stability. The machining time and cost could rise but considering the lifetime warranty of implant products, the reduced feed rate must be followed up.

In turning operations, polymer surface cracks was found at high feed rate [6]. Those cracks were not found in this research. It be caused by the intermittent load occurred in the milling operations. The plastic material should not be severely deformed due to the continuous sliding as happened in the turning operations.

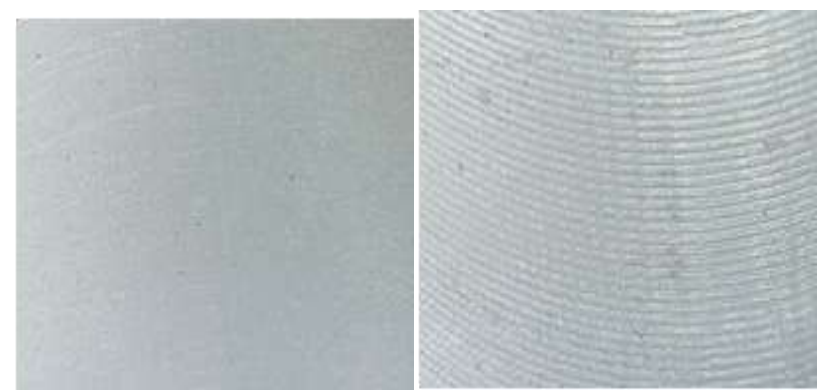

Fig 3: Macro photo of the machined surface at the depth of cut equal to $0.1 \mathrm{~mm}$ and feed rate of $0.05 \mathrm{~mm} / \mathrm{rev}$. (above) and $0.2 \mathrm{~mm} / \mathrm{rev}$ (below)

\section{CONCLUSION}

CNC milling machining process on the UHMWPE biomaterial is capable to produce surface finish qualities with surface roughness below 2 microns. Proper machining parameters must be set with a multiple regression model developed in this study. Feed rate is the most influential parameter in the purpose to obtain better surface quality.

\section{ACKNOWLEDGEMENT}

The authors would like to thank for various institutions on their supports to this research, Vocational School, Universitas Gadjah Mada for financial support and the laboratories of Production, CNC, Material Testing and Metrology for technical assistances.

\section{REFERENCES}

[1] Buechel, F.F., Pappas, M.J., 2011, Principles of Human Joint Replacement Design and Clinical Application, Springer-Verlag Berlin Heidelberg.

[2] Berry, D.J., Trousdale, R.T., Dennis, D.A., Paprosky, W.G., 2012, Revision total hip and knee arthroplasty, Lippincott Williams \& Wilkins.

[3] Bagaria, V., 2016, Arthroplasty - A Comprehensive Review, InTech.

[4] Plastics Design Library, 2013, Fatigue and Tribological Properties of Plastics and Elastomers, William Andrew, ISBN 1884207154, p265

[5] Kinnari, T.J., et al., 2010, Effect of surface roughness and sterilization on bacterial adherence to ultra-high molecular weight polyethylene, Clinical Microbiology and Infection 16 (7), 1036-1041.

[6] Salles, J.L.C., Gonçalves, M.T.T., Effects of Machining Parameters on Surface Quality of the Ultra High Molecular Weight Polyethylene (UHMWPE) Matéria, 2003, 8, 1-10

[7] Lazarević, D., Madić, M., Janković, P., Lazarević, A., 2012, Cutting Parameters Optimization for Surface Roughness in Turning Operation of Polyethylene Using Taguchi Method. Tribology in Industry 34 (2), 68-73.

[8] Song, J., 1997, The Effects of Machining on Structure and Tribological Properties of Ultra High Molecular Weight Polyethylene for Artificial Joint Prostheses, Thesis, Eastern Illinois University

[9] Schmidt, M.A., 2001, Surface Texture and Micromechanics of Ultra High Molecular Weight Polyethylene (UHMWPE) Orthopedic Implant Bearings, Thesis, University of Tennessee-Knoxville

[10] Kurtz, S.M., 2004. The UHMWPE Handbook: UltraHigh Molecular Weight Polyethylene in Total Joint Replacement. Elsevier.

[11] Handoko, Mudjijana, 2012, Kajian Pengaruh Parameter Pemesinan Terhadap Surface Roughness Pada Operasi Bubut Terhadap Bahan Austempered Ductile Iron, Prosiding Seminar Nasional Perkembangan Riset dan Teknologi di Bidang Industri ke 18, ISBN: 978-979-95620-8-1, pp. BT/MB 54-61

[12] Patrick, J.D., 2009, Simulations to Analyze Type I Error and Power in the ANOVA $F$ Test and Nonparametric Alternatives, University of West Florida.

[13] AMETEK.Inc., 2017, What is the difference between roughness, waviness and form?, https://www.taylorhobson.com/learning-zone/faq/what-is-thedifference-between-roughness-waviness-and-form, accessed in Nov 5, 2018, 11:50 a.m. 


\section{BIOGRAPHIES}

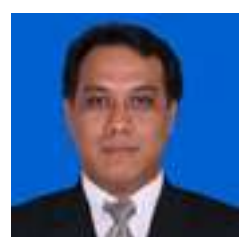

Budi Basuki is a lecturer at the Mechanical Engineering Department, Vocational School, Universitas Gadjah Mada. His research field is the manufacturing technologies. Mr. Basuki published various research papers specifically in manufacturing processes.

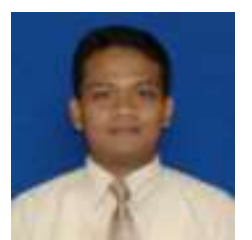

Andhi Akhmad Ismail is a lecturer at the Mechanical Engineering Department, Vocational School, Universitas Gadjah Mada. He has been conducting research in the control and automation technologies. His latest publication was on the development of the ant colony algorithm. 